BNL-112220-2016-JA

\title{
Palladium-Platinum Core-Shell Electrocatalysts for Oxygen Reduction Reaction Prepared with the Assistance of Citric Acid
}

\author{
Lulu Zhang, Shangqian Zhu, Qiaowan Chang, \\ Dong Su, Jeffrey Yue, Zheng Du, Minhua Shao
}

Submitted to ACS catalysis

April 2016

Center For Functional Nanomaterials

Brookhaven National Laboratory

\author{
U.S. Department of Energy \\ USDOE Office of Science (SC), \\ Basic Energy Sciences (BES) (SC-22)
}

Notice: This manuscript has been authored by employees of Brookhaven Science Associates, LLC under Contract No. DE- SC0012704 with the U.S. Department of Energy. The publisher by accepting the manuscript for publication acknowledges that the United States Government retains a non-exclusive, paid-up, irrevocable, world-wide license to publish or reproduce the published form of this manuscript, or allow others to do so, for United States Government purposes. 


\section{DISCLAIMER}

This report was prepared as an account of work sponsored by an agency of the United States Government. Neither the United States Government nor any agency thereof, nor any of their employees, nor any of their contractors, subcontractors, or their employees, makes any warranty, express or implied, or assumes any legal liability or responsibility for the accuracy, completeness, or any third party's use or the results of such use of any information, apparatus, product, or process disclosed, or represents that its use would not infringe privately owned rights. Reference herein to any specific commercial product, process, or service by trade name, trademark, manufacturer, or otherwise, does not necessarily constitute or imply its endorsement, recommendation, or favoring by the United States Government or any agency thereof or its contractors or subcontractors. The views and opinions of authors expressed herein do not necessarily state or reflect those of the United States Government or any agency thereof. 


\title{
Palladium-Platinum Core-Shell Electrocatalysts for Oxygen Reduction Reaction Prepared with the Assistance of Citric Acid
}

\author{
Lulu Zhang ${ }^{\dagger}$, Shangqian Zhu ${ }^{\dagger}$, Qiaowan Chang ${ }^{\dagger}$, Dong Su ${ }^{\ddagger}$, Jeffrey Yue ${ }^{\dagger}$, Zheng Du ${ }^{\$}$, Minhua \\ Shao $^{\dagger, *}$ \\ ${ }^{\dagger}$ Department of Chemical and Biomolecular Engineering, The Hong Kong University of Science \\ and Technology, Clear Water Bay, Kowloon, Hong Kong \\ ${ }^{\ddagger}$ Center for Functional Nanomaterials, Brookhaven National Laboratory, Upton, New York \\ 11973, USA \\ ${ }^{\$}$ National Supercomputing Center in Shenzhen, Shenzhen, Guangdong, 518055, P.R. China \\ *kemshao@ust.hk; Tel.: +852-34692269
}

\begin{abstract}
Core-shell structure is a promising alternative to solid platinum (Pt) nanoparticles as electrocatalyst for oxygen reduction reaction (ORR) in proton exchange membrane fuel cells (PEMFCs). A simple method of preparing palladium (Pd)-platinum (Pt) core-shell catalysts (Pd@Pt/C) in a gram-batch was developed with the assistance of citric acid. The Pt shell deposition involves three different pathways: galvanic displacement reaction between Pd atoms and Pt cations, chemical reduction by citric acid, and reduction by negative charges on Pd surfaces. The uniform ultrathin $(\sim 0.4 \mathrm{~nm})$ Pt shell was characterized by in situ X-ray diffraction (XRD), and High angle annular dark-field scanning transmission electron microscopy (HAADFSTEM) images combined with electron energy loss spectroscopy (EELS). Compared with stateof-the-art Pt/C, the Pd@Pt/C core-shell catalyst showed four times higher Pt mass activity and much better durability upon potential cycling. Furthermore, both the mass activity and durability were comparable to that of Pd@Pt/C synthesized by a Cu-mediated-Pt-displacement method, which is more complicated and difficult for mass production.
\end{abstract}

Keywords: Electrocatalysis, fuel cells, underpotential deposition, synchrotron, durability 


\section{Introduction}

The commercialization of proton exchange membrane fuel cells (PEMFCs) has been hindered by the sluggish reaction kinetics of the oxygen reduction reaction (ORR) that requires a high $\mathrm{Pt}$ loading ( $>0.4 \mathrm{mg} \mathrm{cm}^{-2}$ ) at the cathode. ${ }^{1}$ In order for the fuel cell products to be cost competitive, advanced ORR catalysts with at least 4 times activity improvement over state-of-the-art Pt/C are highly demanding. Recent intensive research efforts have led to the development of less expensive and more active ORR catalysts including advanced Pt alloys, ${ }^{2}$ carbon based nonprecious metal catalysts, ${ }^{1 e, 3}$ and core-shell catalysts. ${ }^{4}$ Among them, the core-shell structure consisting of a thin layer of Pt deposited on the surface of a lower cost nanoparticle has attracted considerable attention. As only surface atoms actively participate in the electrochemical reactions, this approach can significantly enhance the utilization of Pt. The core-shell structure can also provide significant benefits in cost reduction since the core is less expensive than Pt. In addition, the geometric and electronic effects induced by the underlying substrate can enhance the activity of the Pt shell for the ORR, leading to greater activity per mass of Pt than that expected based on the utilization improvement alone. ${ }^{5}$

There are a few known methods to synthesize core-shell structures: (1) dealloying that involves the electrochemical/chemical etching of less noble metal from bulk Pt alloys resulting in a Pt-skin like surface (a few nm thick) covering the Pt alloy core; ${ }^{2 a,}{ }^{6}$ (2) Wet-chemistry that involves the deposition of Pt-based shell (1-3 nm thick) on the foreign metal cores with the assistance of reducing agents, such as $\mathrm{NaBH}_{4}, \mathrm{H}_{2}, \mathrm{CO}$, ethanol, ascorbic acid, ethylene glycol, etc.; ${ }^{7}$ (3) Spontaneous deposition that involves the galvanic displacement between surface atoms of the metallic core and Pt cations in the deposition solution; ${ }^{8}$ (4) Cu-mediated-Pt-displacement method that involves the displacement of an underpotentially deposited (UPD) Cu monolayer by $\mathrm{Pt}^{4}{ }^{4}$ In this method, the Cu monolayer deposited on the core (for example Pd) then is displaced by Pt via a surface limited redox replacement (SLRR) reaction: $\mathrm{Pd@Cu}+\mathrm{PtCl}_{4}{ }^{2-} \rightarrow \mathrm{Pd} @ \mathrm{Pt}+$ $\mathrm{Cu}^{2+}+4 \mathrm{Cl}^{-}$. Recent studies have shown that the SLRR reaction is rather complicated and poorlycontrolled resulting in formation of 3D Pt islands instead of a uniform overlayer, ${ }^{9}$ especially in the large batch size synthesis. ${ }^{10}$ The spontaneous deposition method also has the same issue since it involves the similar reaction mechanism. Herein, we reported a simple method of preparing 
Pd-Pt core-shell catalysts (denoted as Pd@Pt/C) in a gram-batch with the assistance of citric acid. Comparing with other reducing agents, the reducing power of citric acid is neither too strong nor too week and allows the reduction reaction to occur at the room temperature, which significantly simplifies the reaction process. In addition, the strong interaction of citric acid with metals may reduce the Pd dissolution and introduce charge transfer from adsorbed citric acid molecules to Pd surface, which can also be used to reduce Pt cations. Compared with Pt-M alloys ( $\mathrm{M}=\mathrm{Fe}$, Co, $\mathrm{Ni}$, etc.), Pd@Pt/C catalysts do not have the contamination issue of membrane and ionomer caused by the transition metal cations dissolved during fuel cell operation.

The synthesis of Pd@Pt/C catalysts was conducted by adding a deaerated $10 \mathrm{mM} \mathrm{K}_{2} \mathrm{PtCl}_{4}$ and citric acid solution into a suspension consisting of $500 \mathrm{mg}$ of Pd/C nanoparticles (TKK, $35 \mathrm{wt}$ \%) in $15 \mathrm{~min}$. The mixture was stirred for another $45 \mathrm{~min}$ to complete the Pt deposition. The amount of Pt deposited on $\mathrm{Pd} / \mathrm{C}$ nanoparticles at different reaction time was obtained by inductively coupled plasma - mass spectrometry (ICP-MS) measurements, and shown in Figure 1 (red square). The rate of Pt deposition can be divided into three regions. Within the first 2 min of deposition, the Pt loading (wt.\%) increased sharply from 0 to 5.8\%. In the second region between 2 and 20 min, the Pt loading increased linearly with a rate of $0.2 \%$ per min, which was much slower than that in the first region. At the end of $20 \mathrm{~min}$, the Pt loading was 9.5\%. In the last 40 min, the further growth of Pt was even more difficult with a growth rate of $0.04 \%$ per min. At the end of the reaction (60 min), the final Pt loading reached $11.2 \%$. The Pd loading as a function of time is also shown in Figure 1 (blue square). As expected, the Pd wt.\% decreased with time as more Pt atoms were deposited. The Pd loading decreased from 31.6\% for the pristine Pd/C to 27.5\% for the final Pd@Pt/C catalysts.

There are three possible mechanisms for Pt deposition on Pd surfaces. The first one involves the sacrificial dissolution of Pd atoms (galvanic displacement) due to the difference in the standard redox potentials between $\mathrm{Pd} / \mathrm{PdCl}_{4}{ }^{-}$(0.591 V) and $\mathrm{Pt} / \mathrm{PtCl}_{4}{ }^{-}(0.755 \mathrm{~V}): \mathrm{Pd}+\mathrm{PtCl}_{4}{ }^{-} \rightarrow \mathrm{Pt}$ $+\mathrm{PdCl}_{4}{ }^{-}$. Such phenomena have been extensively used to make hollow and core-shell structures using both noble and non-noble metal nanoparticles as seeds. The second mechanism is due to the reduction of $\mathrm{Pt}$ cations by citric acid via a chemical reaction: citric acid $+\mathrm{PtCl}_{4}^{-} \rightarrow \mathrm{Pt}+4 \mathrm{Cl}^{-}$ + oxidation products. The last mechanism involves the spontaneous adsorption of Pt cations on Pd surfaces along with electron transfer from the later to the adsorbates resulting in reduced Pt 
atoms deposited on Pd surfaces. It has been reported that citric acid or citrate can be adsorbed on metallic surface via carboxylate groups. ${ }^{11}$ The strong interactions of citric acid molecules with $\operatorname{Pd}(111)$ and Pt monolayer decorated $\operatorname{Pd}(111)$ were confirmed in our molecular dynamic simulations (calculation details can be found in the Supporting Information). The highly negative interaction energy for citric acid (50 molecules) on Pd (-1744.5 kcal mol $\left.{ }^{-1}\right)$ and Pt monolayer ($2011.4 \mathrm{kcal} \mathrm{mol}^{-1}$ ) suggested relatively stable adsorption on both surfaces. The adsorption also induced a partial charge transfer from the citric acid to Pd particle, ${ }^{12}$ which can be used to reduce Pt cations adsorbed on the surface.

The theoretical Pd loadings in Pd@Pt/C samples formed via the sacrificial dissolution of Pd (blue dashed line) and chemical reduction by citric acid/negative charge on Pd surfaces (blue dotted line) as a function of deposition time were calculated based on the Pt wt.\% (red square) and shown in Figure 1. It is easy to understand that the Pd loadings in the first mechanism is lower since Pt deposition is a result of Pd dissolution in this case. The Pd loadings of Pd@Pt/C samples at different reaction time measured by ICP-MS are between the dashed and dotted line in Figure 1. This result implies that the Pt deposition may involve both Pd dissolution and chemical reduction by citric acid/negative charges on Pd surfaces.

Figure 2A shows a typical high angle annular dark-field scanning transmission electron microscopy (HAADF-STEM) image of core-shell catalysts after 60 min of reaction. A single core-shell particle and its electron energy loss spectroscopy (EELS) line profiles of Pt and Pd across the particle are shown in Figure 2B. The two sharp peaks at two sides of the Pt profile indicate the Pt shell on the Pd core. The thickness of the Pt shell determined in the line scan is about $0.4 \mathrm{~nm}$, which is equivalent to $1 \sim 2$ atomic layer. The quality of the Pt shell was also evaluated using a qualitative method developed recently, ${ }^{10}$ which utilizes the ability of Pd to absorb hydrogen to form a Pd hydride structure resulting in a lattice expansion. Pt and Pd have the same fcc structure with a similar lattice constant which makes these two materials inseparable in regular XRD measurements. Unlike Pd, Pt cannot absorb $\mathrm{H}_{2}$. Thus, in a $\mathrm{H}_{2}$ environment, the XRD peaks of Pd shift to lower angles according to the Bragg Equation, while those of Pt remain at the same positions. In other words, the XRD peaks are expected to be split in $\mathrm{H}_{2}$ for a mixture consisting of Pd and Pt nanoparticles. ${ }^{10 a}$ For the core-shell materials with an ultrathin Pt shell (1-2 atomic layers), $\mathrm{H}_{2}$ is expected to easily penetrate through the Pt shell into 
the Pd core, resulting in a uniform XRD peak shifting in a $\mathrm{H}_{2}$ atmosphere. Figure 2C compares the XRD pattern of $\mathrm{Pd@Pt/C}$ in $\mathrm{He}$ and $\mathrm{H}_{2}$ atmospheres measured in a customized cell. In a $\mathrm{H}_{2}$ environment, the XRD peak corresponding to the $\operatorname{Pd}(111)$ plane shifted uniformly to a lower angle. This result confirms the absence of large Pt clusters in Pd@Pt/C otherwise a shoulder peak associated with Pt would appear at the position of $\mathrm{Pt}(111)$. Of course, this technique cannot tell whether there are pinholes in the Pt shell.

The cyclic voltammetries (CVs) of Pd@Pt/C (red line) and its core Pd/C (dashed black line) in a $\mathrm{N}_{2}$-saturated $0.1 \mathrm{M} \mathrm{HClO}_{4}$ solution are compared in Figure 3A. The oxide layer formation and its reduction shifted to a more positive potential by $\sim 50 \mathrm{mV}$ when $\mathrm{Pd} / \mathrm{C}$ was modified by a Pt shell. The delayed oxide layer formation on the catalyst surface resulted in a significant improvement on ORR activity. The CV of Pd@Pt/C (Pd: 27\%, Pt: 18\%) prepared via the Cumediated-Pt-displacement reaction (denoted as Pd@Pt/C (UPD)) is also included in the same plot for comparison. Clearly, the CVs of these two core-shell catalysts prepared by different methods are very similar. Figure 3B compares the oxygen reduction polarization curves (positive scan) of $\mathrm{Pd@Pt/C} \mathrm{and} \mathrm{state-of-the-art} \mathrm{Pt/C} \mathrm{in} \mathrm{an} \mathrm{oxygen-saturated} 0.1 \mathrm{M} \mathrm{HClO}_{4}$ solution. The Pt loadings for Pd@Pt/C, Pd@Pt/C (UPD) and Pt/C are 2.45, 4.0 and $24 \mu \mathrm{g} \mathrm{cm}^{-2}$, respectively. The corresponding initial Pt mass activities (kinetic currents at $0.9 \mathrm{~V}$ (vs RHE) normalized to the Pt mass on the electrode) are 0.78, 0.95 and $0.2 \mathrm{~A} \mathrm{mg}^{-1}$ (Figure 3C). The activity of Pd@Pt/C prepared by citric acid reduction is almost 4 times higher than that of Pt/C, and close to that of one prepared by the complicated Cu-mediated-Pt-displacement. The PGM (platinum group metal) mass activities are $0.23,0.38$ and $0.2 \mathrm{~A} \mathrm{mg}^{-1}$, respectively. Considering the lower price of Pd than Pt, the cost reduction of core-shell catalysts is still significant. ${ }^{1 \mathrm{e}}$ The respective electrochemical areas (ECAs) of Pd@Pt/C and Pt/C are 142 and $85 \mathrm{~m}^{2} \mathrm{~g}^{-1}$,Pt based on the hydrogen UPD charges assuming $210 \mu \mathrm{C} \mathrm{cm}^{-2}$ for a full coverage. The corresponding specific activities are 0.55 and $0.24 \mathrm{~A} \mathrm{~cm}^{-2}$ indicating the activity enhancement caused by the Pd core in Pd@Pt/C. It is worth noting that citric acid was also added in the Cu-Pt displacement reaction solution in the synthesis of Pd@Pt/C (UPD). ${ }^{10 a}$ In the absence of citric acid, the ORR activity of Pd@Pt/C (UPD) was only $0.38 \mathrm{~A} \mathrm{mg}^{-1} \cdot{ }^{10 \mathrm{a}}$ The role of citric acid is probably different in chemical reduction and Cu-mediated-Pt-displacement reactions, which will be discussed in a separate report. 
The activity of Pd@Pt/C samples as a function of Pt deposition time is shown in Figure 3C (black square). After only 2 min of deposition, the activity of Pd@Pt/C (0.25 A mg $\left.{ }^{-1}\right)$ is already higher than that of Pt/C. Upon further deposition, the Pt mass activity increases sharply and reaches $0.68 \mathrm{~A} \mathrm{mg}^{-1}$ after $20 \mathrm{~min}$ of deposition. After that, the activity slowly increases to $0.78 \mathrm{~A}$ $\mathrm{mg}^{-1}$ with additional 40 min of deposition. The activity trend correlates well with the Pt wt.\% shown in Figure 1. The morphology of the Pt shell may play an important role in determining the activity of Pd@Pt/C with various Pt loadings on the Pd core. In the early stage of Pt deposition, Pt nuclei start to initiate either via the reaction with surface Pd atoms or reduction by citric acid/surface charge. With further deposition of Pt atoms, these nuclei grow to relatively larger clusters. Both nuclei and clusters only consist of a limited number of Pt atoms and are isolated on the Pd surface. The ORR activity of these low coordinated Pt atoms are expected to be low. ${ }^{13}$ When the Pt loading is higher enough, for instance, $10 \%$ in the current study, most of individual Pt cluster is able to connect with each other forming a continuous Pt overlayer, which has a much lower dispersion of low coordinated edge atoms than the former. The formation of the continuous and uniform Pt shell is believed to be responsible for the high activity of the final Pd@Pt/C catalyst.

Citric acid is believed to play a crucial role in smoothening the Pt shell. Large three dimensional (3D) clusters or thick films have been commonly observed during spontaneous deposition of foreign metal atoms on metallic substrates/cores. ${ }^{\text {8b, 9c, 10a, } 14}$ The deposition position of the foreign atom is difficult to control in the galvanic displacement reaction, resulting in the formation of 3D islands instead of a uniform overlayer. The poor Pt shell was also realized recently in the scaling up synthesis of $\mathrm{Pd} @ \mathrm{Pt} / \mathrm{C}$ (UPD) involving the $\mathrm{Cu}-\mathrm{Pt}$ galvanic displacement reaction. ${ }^{10 a}$ To further reveal the importance of citric acid in improving the quality of the Pt shell, a Pd@Pt/C sample was synthesized without using citric acid in the deposition solution. The ORR activity at $0.9 \mathrm{~V}$ of this sample was only $0.31 \mathrm{~A} \mathrm{mg}^{-1}$, which was $45 \%$ of that synthesized with the assistance of citric acid. A shoulder peak at the position of Pt in the XRD pattern in measured in $\mathrm{H}_{2}$ confirmed the formation of relatively large Pt clusters (Figure S1).

The stability of the core-shell catalyst was also tested with a square-wave signal between 0.65 and $1.0 \mathrm{~V}$ in an $\mathrm{O}_{2}$-saturated $0.1 \mathrm{M} \mathrm{HClO}_{4}$ solution. The results are shown in the inset of Figure 3B. After 10000 cycles, the Pt mass activity dropped from 0.78 to $0.64 \mathrm{~A} \mathrm{mg}^{-1}$ with a degradation 
rate of $18 \%$. For comparison, the degradation rate of $\mathrm{Pt} / \mathrm{C}$ is $42 \%$ under the same testing condition. The much lower degradation rate of Pd@Pt/C implies that the core-shell structure may undergo a self-healing mechanism during potential cycling. ${ }^{15}$ Compared with Pt, Pd is much easier to be dissolved. With continuous removal of Pd in the core through pinholes, the particles gradually shrink and the rearrangement of Pt atoms on the surface are able to form a more uniform and thicker Pt layer, which in turn improves the stability of the core-shell structure. ${ }^{15}$ The durability of Pd@Pt/C is also comparable to that of the core-shell sample prepared involving $\mathrm{Cu}$ UPD with a degradation rate of $16 \%$.

\section{Conclusions}

A simple method of preparing Pd@Pt/C core-shell catalysts in a gram-batch for oxygen reduction reaction was developed with the assistance of citric acid. The Pt deposition seems to involve three different pathways: galvanic displacement reaction between $\mathrm{Pd}$ atoms and $\mathrm{Pt}$ cations, chemical reduction by citric acid, and reduction by negative charges on Pd surfaces. Citric acid was demonstrated to play a crucial role in controlling the morphology of the Pt shell. The good quality of the ultrathin Pt shell $(\sim 0.4 \mathrm{~nm})$ was characterized by in situ XRD and HAADF-EELS. It was further confirmed by the high ORR activity and durability in the electrochemical evaluation. Compared with state-of-the-art Pt/C catalysts, the Pd@Pt/C coreshell catalyst synthesized with the assistance of citric acid showed almost four times higher Pt mass activity and much better durability upon potential cycling. Furthermore, both the mass activity and durability were comparable to that of Pd@Pt/C synthesized by a Cu-UPD-Ptdisplacement method, which is more complicated and difficult for mass production. Owing to their excellent electrochemical performance and easiness in synthesis, Pd@Pt/C core-shell catalysts are expected to play an important role in next generation PEMFCs.

\section{Supporting Information}

Experimental and calculation details, XRD pattern. This material is available free of charge via the Internet at http://pubs.acs.org.

\section{Acknowledgement}

Authors would like to thank the financial support from the Research Grant Council of the Hong Kong Special Administrative Region (IGN13EG05 and 26206115) and a startup fund from the 
Hong Kong University of Science and Technology. The work at the Brookhaven National Laboratory was supported by the U.S. Department of Energy, Office of Science, Office of Basic Energy Sciences, under Contract No. DE-AC02-98CH10886. Beamline X18A at the NSLS is supported in part by the Synchrotron Catalysis Consortium (DOE BES grant DE-FG0203ER15688).

\section{References}

1. (a) Gasteiger, H. A.; Kocha, S. S.; Sompalli, B.; Wagner, F. T. Appl. Catal. B 2005, 56, 9-35; (b) Gasteiger, H. A.; Markovic, N. M. Science 2009, 324, 48-49; (c) Debe, M. K. Nature 2012, 486, 43-51; (d) Ball, S. In Electrocatalysis in Fuel Cells: A Non- and Low- Platinum Approach, Shao, M., Ed. Springer: London, 2013; pp 561-588; (e) Shao, M.; Chan, Q.; Dodelet, J.-P.; Chenitz, R. Chem. Rev. 2016, 116, 3594-3657.

2. (a) Han, B.; Carlton, C. E.; Kongkanand, A.; Kukreja, R. S.; Theobald, B. R.; Gan, L.; O'Malley, R.; Strasser, P.; Wagner, F. T.; Shao-Horn, Y. Energy Environ. Sci. 2015, 8, 258-266; (b) Wang, Y.-J.; Zhao, N.; Fang, B.; Li, H.; Bi, X. T.; Wang, H. Chem. Rev. 2015, 115, 3433-3467; (c) Wang, D.; Xin, H. L.; Hovden, R.; Wang, H.; Yu, Y.; Muller, D. A.; DiSalvo, F. J.; Abruña, H. D. Nat. Mat. 2013, 12, 81-87; (d) Chen, C.; Kang, Y.; Huo, Z.; Zhu, Z.; Huang, W.; Xin, H. L.; Snyder, J. D.; Li, D.; Herron, J. A.; Mavrikakis, M.; Chi, M.; More, K. L.; Li, Y.; Markovic, N. M.; Somorjai, G. A.; Yang, P.; Stamenkovic, V. R. Science 2014, 343, 1339-1343; (e) Stamenkovic, V. R.; Fowler, B.; Mun, B. S.; Wang, G.; Ross, P. N.; Lucas, C. A.; Markovic, N. M. Science 2007, 315, 493-497; (f) van der Vliet, D. F.; Wang, C.; Tripkovic, D.; Strmcnik, D.; Zhang, X. F.; Debe, M. K.; Atanasoski, R. T.; Markovic, N. M.; Stamenkovic, V. R. Nat. Mater. 2012, 11, 1051-1058; (g) Choi, S.-I.; Xie, S.; Shao, M.; Odell, J. H.; Lu, N.; Peng, H.-C.; Protsailo, L.; Guerrero, S.; Park, J.; Xia, X.; Wang, J.; Kim, M. J.; Xia, Y. Nano Lett. 2013, 13, 3420-3425; (h) Huang, X.; Zhao, Z.; Cao, L.; Chen, Y.; Zhu, E.; Lin, Z.; Li, M.; Yan, A.; Zettl, A.; Wang, Y. M.; Duan, X.; Mueller, T.; Huang, Y. Science 2015, 348, 1230-1234; (i) Cui, C.; Gan, L.; Li, H.-H.; Yu, S.-H.; Heggen, M.; Strasser, P. Nano Lett. 2012, 12, 5885-5889.

3. (a) Dodelet, J.-P. In Electrocatalysis in Fuel Cells, Shao, M., Ed. Springer London: 2013; Vol. 9, pp 271-338; (b) Proietti, E.; Jaouen, F.; Lefèvre, M.; Larouche, N.; Tian, J.; Herranz, J.; Dodelet, J.-P. Nat. Commun. 2011, 2, 416; (c) Jaouen, F.; Proietti, E.; Lefèvre, M.; Chenitz, R.; Dodelet, J.-P.; Wu, G.; Chung, H. T.; Johnston, C. M.; Zelenay, P. Energy Environ. Sci. 2011, 4, 114-130; (d) Wu, G.; More, K. L.; Johnston, C. M.; Zelenay, P. Science 2011, 332, 443-447.

4. (a) Adzic, R. R. Electrocatalysis 2012, 3, 163-169; (b) Adzic, R. R.; Zhang, J.; Sasaki, K.; Vukmirovic, M. B.; Shao, M.; Wang, J. X.; Nilekar, A. U.; Mavrikakis, M.; Valerio, J. A.; Uribe, F. Top. Catal. 2007, 46, 249-262; (c) Kuttiyiel, K. A.; Sasaki, K.; Su, D.; Wu, L.; Zhu, Y.; Adzic, R. R. Nat. Commun. 2014, 5, 5185; (d) Sasaki, K.; Naohara, H.; Cai, Y.; Choi, Y. M.; Liu, P.; Vukmirovic, M. B.; Wang, J. X.; Adzic, R. R. Angew. Chem. Int. Ed. 2010, 49, 8602-8607; (e) Sasaki, K.; Naohara, H.; Choi, Y.; Cai, Y.; Chen, W.-F.; Liu, P.; Adzic, R. R. Nat. Commun. 2012, 3,1115; (f) Choi, S.-I.; Shao, M.; Lu, N.; Ruditskiy, A.; Peng, H.-C.; Park, J.; Guerrero, S.; Wang, J.; Kim, M. J.; Xia, Y. Acs Nano 2014, 8, 10363-10371; (g) Shao, M. H.; Shoemaker, K.; Peles, A.; Kaneko, K.; Protsailo, L. J. Am. Chem. Soc. 2010, 132, 9253-9255; (h) Higuchi, E.; Okada, K.; Chiku, M.; Inoue, H. Electrochim. Acta 2015, 179, 100-107.

5. (a) Zhang, J. L.; Vukmirovic, M. B.; Xu, Y.; Mavrikakis, M.; Adzic, R. R. Angew. Chem. Int. Ed. 2005, 44, 2132-2135; (b) Shao, M.; Peles, A.; Shoemaker, K.; Gummalla, M.; Njoki, P. N.; Luo, J.; Zhong, C.-J. J. Phys. Chem. Lett. 2011, 2, 67-72.

6. (a) Strasser, P.; Koh, S.; Greeley, J. Phys. Chem. Chem. Phys. 2008, 10, 3670-3683; (b) Oezaslan, M.; Strasser, P. J. Power Sources 2011, 196, 5240-5249; (c) Hasché, F.; Oezaslan, M.; Strasser, P. ChemCatChem 2011, 3, 1805-1813; (d) Mani, P.; Srivastava, R.; Strasser, P. J. Power Sources 2011, 196, 
666-673; (e) Strasser, P.; Koh, S.; Anniyev, T.; Greeley, J.; More, K.; Yu, C.; Liu, Z.; Kaya, S.; Nordlund, D.; Ogasawara, H.; Toney, M. F.; Nilsson, A. Nat. Chem. 2010, 2, 454-460.

7. (a) Liu, L.; Samjeske, G.; Nagamatsu, S.-i.; Sekizawa, O.; Nagasawa, K.; Takao, S.; Imaizumi, Y.; Yamamoto, T.; Uruga, T.; Iwasawa, Y. J. Phys. Chem. C 2012, 116, 23453-23464; (b) Choi, R.; Choi, S.-I.; Choi, C. H.; Nam, K. M.; Woo, S. I.; Park, J. T.; Han, S. W. Chem. - Eur. J. 2013, 19, 8190-8198; (c) Zhang, G.; Shao, Z.-G.; Lu, W.; Xie, F.; Xiao, H.; Qin, X.; Yi, B. Appl. Catal. B 2013, 132-133, 183-194; (d) Zhang, Y.; Hsieh, Y.-C.; Volkov, V.; Su, D.; An, W.; Si, R.; Zhu, Y.; Liu, P.; Wang, J. X.; Adzic, R. R. ACS Catal. 2014, 4, 738-742; (e) Xie, S.; Choi, S.-I.; Lu, N.; Roling, L. T.; Herron, J. A.; Zhang, L.; Park, J.; Wang, J.; Kim, M. J.; Xie, Z.; Mavrikakis, M.; Xia, Y. Nano Lett. 2014, 14, 3570-3576; (f) Wang, H; Jiang, K; Chen Q.L.; Xie, Z.X.; Cai, W.B. Chem. Commun. 2016, 52, 374-377.

8. (a) Dai, Y.; Chen, S. ACS Appl. Mater. Inter. 2015, 7, 823-829; (b) Brankovic, S.; McBreen, J.; Adžić, R. J. Electroanal. Chem. 2001, 503, 99-104; (c) Wang, D.; Xin, H. L.; Yu, Y.; Wang, H.; Rus, E.; Muller, D. A.; Abruña, H. D. J. Am. Chem. Soc. 2010, 132, 17664-17666.

9. (a) Bae, S.-E.; Gokcen, D.; Liu, P.; Mohammadi, P.; Brankovic, S. R. Electrocatalysis 2012, 3, 203210; (b) Gokcen, D.; Bae, S.-E.; Brankovic, S. R. Electrochim. Acta 2011, 56, 5545-5553; (c) Gokcen, D.; Yuan, Q.; Brankovic, S. R. J. Electrochem. Soc. 2014, 161, D3051-D3056; (d) Cappillino, P. J.; Sugar, J. D.; El Gabaly, F.; Cai, T. Y.; Liu, Z.; Stickney, J. L.; Robinson, D. B. Langmuir 2014, 30, 4820-4829.

10. (a) Humbert, M.; Smith, B.; Wang, Q.; Ehrlich, S.; Shao, M. Electrocatalysis 2012, 3, 298-303; (b) Shao, M.; Smith, B. H.; Guerrero, S.; Protsailo, L.; Su, D.; Kaneko, K.; Odell, J. H.; Humbert, M. P.; Sasaki, K.; Marzullo, J.; Darling, R. M. Phys. Chem. Chem. Phys. 2013, 15, 15078-15090.

11. Xiong, Y.; McLellan, J. M.; Yin, Y.; Xia, Y. Angew. Chem Int. Ed. 2007, 119, 804-808.

12. Maillard, M.; Huang, P.; Brus, L. Nano Lett. 2003, 3, 1611-1615.

13. Shao, M.; Peles, A.; Shoemaker, K. Nano Lett. 2011, 11, 3714-3719.

14. Jayaraju, N.; Vairavapandian, D.; Kim, Y. G.; Banga, D.; Stickney, J. L. J. Electrochem. Soc. 2012, 159, D616-D622.

15. Sasaki, K.; Naohara, H.; Cai, Y.; Choi, Y. M.; Liu, P.; Vukmirovic, M. B.; Wang, J. X.; Adzic, R. R. Angew. Chem Int. Ed. 2010, 49, 8602-8607. 


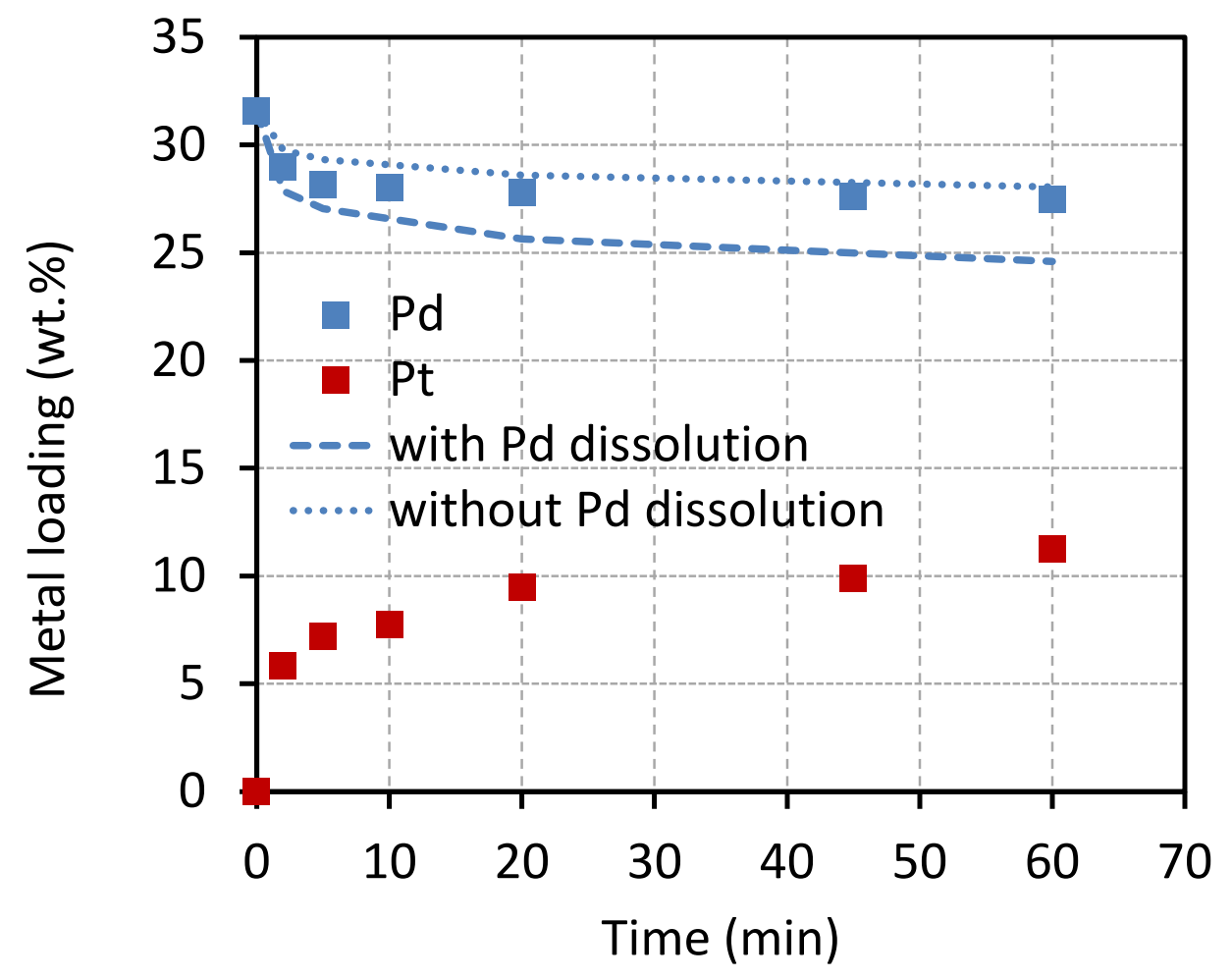

Figure 1. The metal loadings (wt.\%) measured from ICP-MS of Pd@Pt/C catalysts at different reaction time during the spontaneous deposition of $\mathrm{Pt}$ on $\mathrm{Pd}$ nanoparticles. The dashed and dotted lines represent the theoretical Pd wt.\% calculated from the measured Pt wt.\% with and without involving Pd dissolution during Pt deposition. 

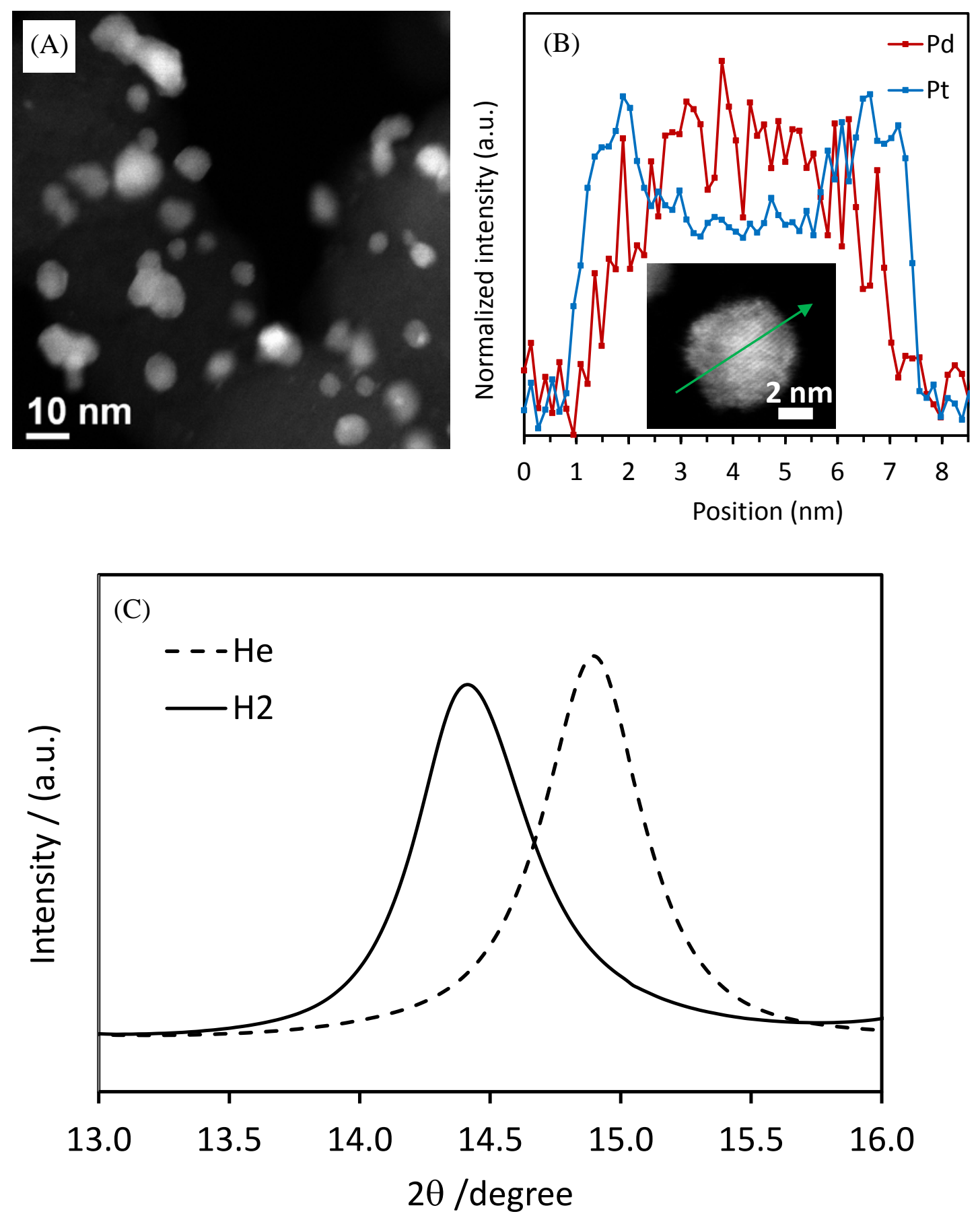

Figure 2. Figure 2. A typical HAADF-STEM image of Pd@Pt/C core-shell catalysts after 60 min of reaction (A) and EELS line scan profiles of Pt (blue) and Pd (red) of a single Pd@Pt coreshell particle (inset) (B). The XRD peak positions of (111) reflection of Pd@Pt/C in He (dashed line) and $\mathrm{H}_{2}$ (solid line) atmospheres (C). The $\mathrm{Mo} \mathrm{K \alpha}(\lambda=0.7107 \AA)$ incident radiation was used in XRD measurements. 

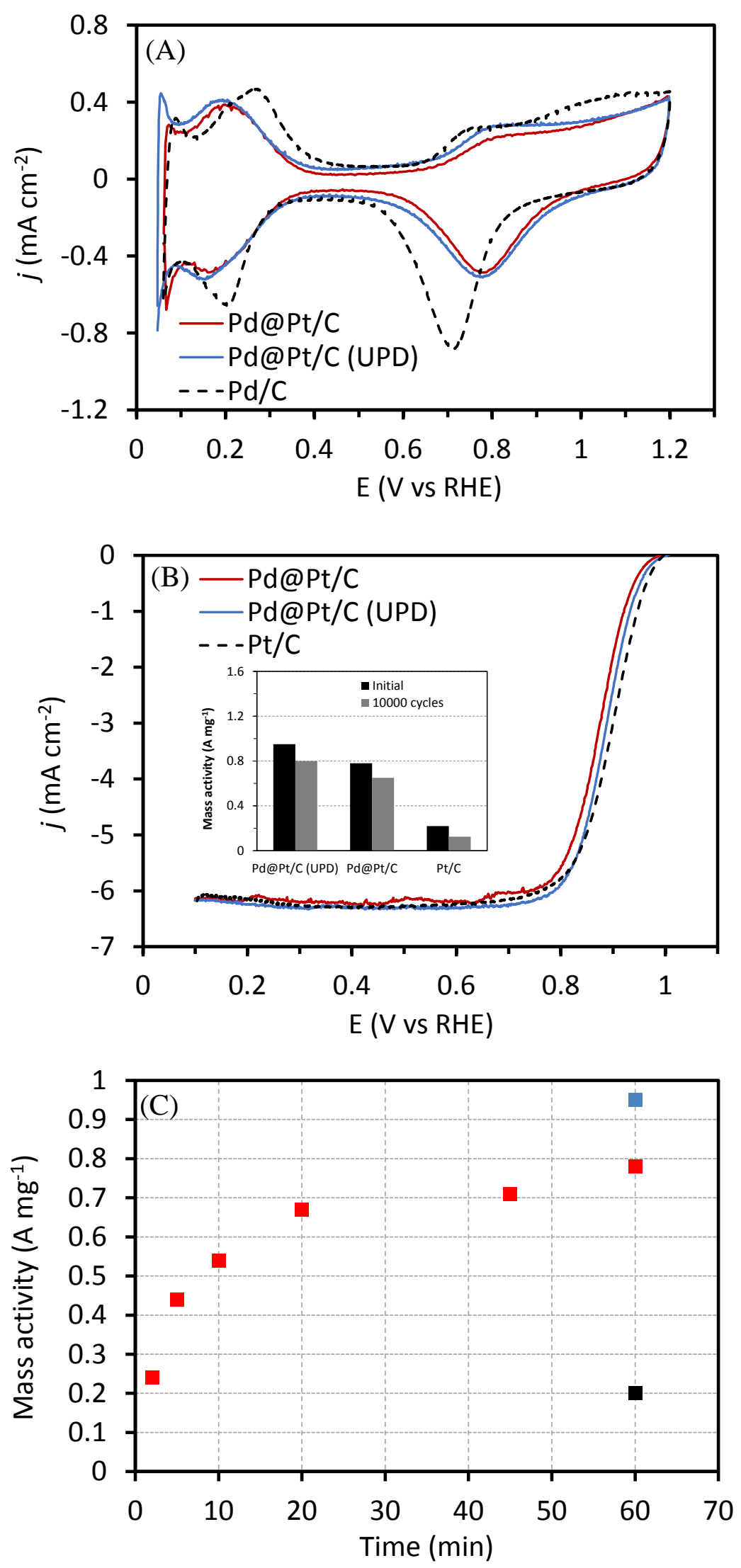
Figure 3. Comparisons of cyclic voltammetry curves of Pd@Pt/C, Pd@Pt/C (UPD) and Pd/C in a $\mathrm{N}_{2}$-saturated $0.1 \mathrm{M} \mathrm{HClO}_{4}$ solution at a scanning rate of $50 \mathrm{mV} \mathrm{s}^{-1}(\mathrm{~A})$; oxygen reduction polarization curves (positive-going) of Pd@Pt/C, Pd@Pt/C (UPD) and Pt/C in a $\mathrm{O}_{2}$-saturated 0.1 $\mathrm{M} \mathrm{HClO}_{4}$ solution at a scanning rate of $10 \mathrm{mV} \mathrm{s}^{-1}$ and rotation speed of $1600 \mathrm{rpm}$ (B); and Pt mass activities of Pd@Pt/C synthesized at different time (red square), Pd@Pt/C (UPD) (blue square) and $\mathrm{Pt} / \mathrm{C}$ (black square) at $0.9 \mathrm{~V}(\mathrm{C})$. The currents were normalized to the geometric area of the rotating disk electrode $\left(0.196 \mathrm{~cm}^{2}\right)$. The Pd loadings in Pd@Pt/C, Pd@Pt/C (UPD) and Pd/C were 8.0, 7.7 and $10 \mu \mathrm{g} \mathrm{cm}^{-2}$, respectively. The Pt loadings in Pd@Pt/C, Pd@Pt/C (UPD) and Pd/C were 2.45, 4 and $24 \mu \mathrm{g} \mathrm{cm}^{-2}$, respectively. The inset of (B) compares the Pt mass activities of Pd@Pt/C, Pd@Pt/C (UPD) and Pt/C before and after 10000 potential cycles between 0.65 and $1.0 \mathrm{~V}$. The data of Pd@Pt/C (UPD) (blue square) and Pt/C (black square) are not associated with time. 
TOC Graph

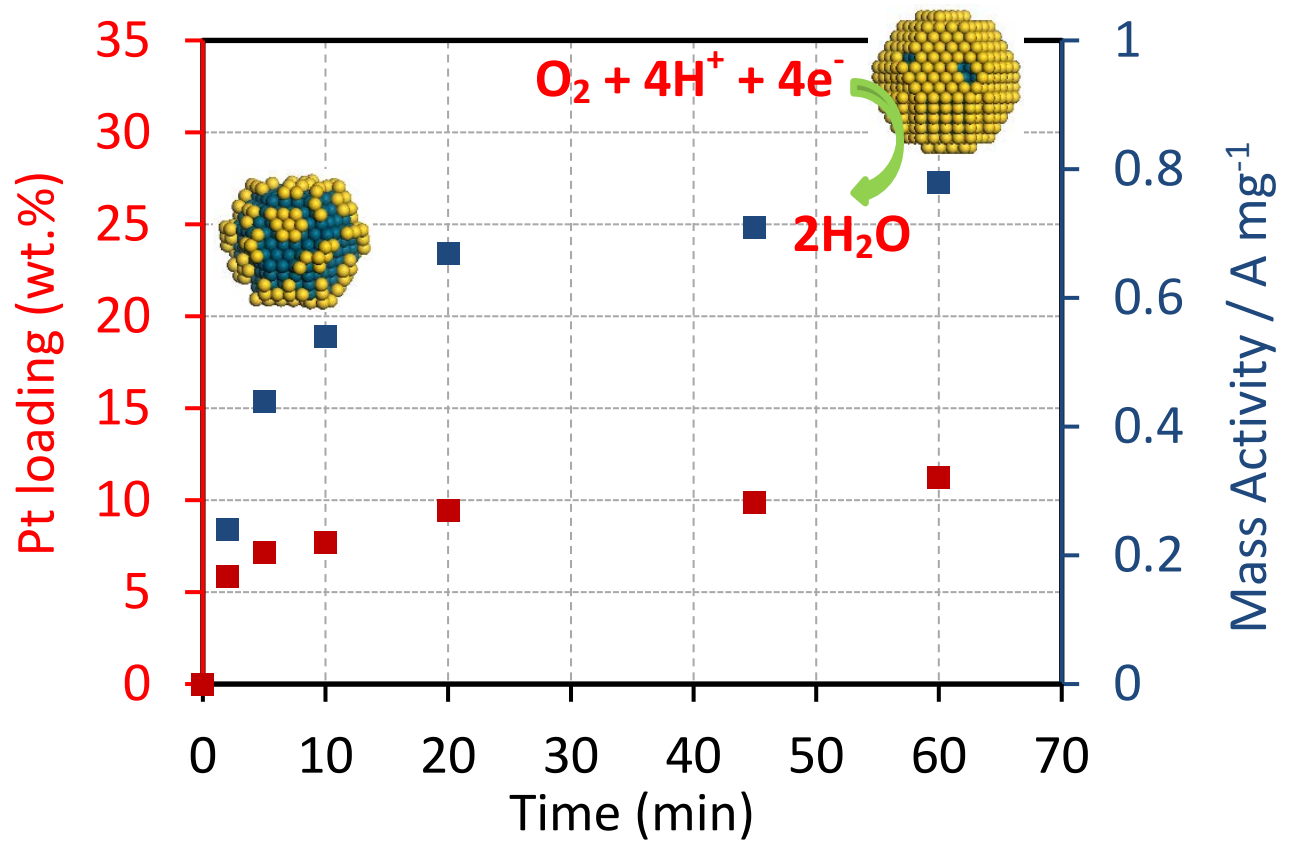

